\title{
Airway Obstruction
}

National Cancer Institute

\section{Source}

National Cancer Institute. Airway Obstruction. NCI Thesaurus. Code C50456.

Blockage of air flow in the respiratory tract. 